\title{
Spiculous skeleton formation in the freshwater sponge Ephydatia fluviatilis under hypergravity conditions
}

\author{
Martijn C Bart ${ }^{\text {Corresp., }}{ }^{1}$, Sebastiaan J de Vet ${ }^{2,3}$ ， Didier M de Bakker ${ }^{4}$ ， Brittany E Alexander ${ }^{1}$, Dick van Oevelen \\ ${ }^{5}$, E. Emiel van Loon ${ }^{6}$, Jack J W A van Loon ${ }^{7}$, Jasper M de Goeij ${ }^{1}$ \\ ${ }^{1}$ Department of Freshwater and Marine Ecology, Institute for Biodiversity and Ecosystem Dynamics, University of Amsterdam, Amsterdam, The \\ Netherlands \\ ${ }^{2}$ Earth Surface Science, Institute for Biodiversity and Ecosystem Dynamics, University of Amsterdam, Amsterdam, Netherlands \\ 3 Taxonomy \& Systematics, Naturalis Biodiversity Center, Leiden, The Netherlands \\ 4 Microbiology \& Biogeochemistry, NIOZ Royal Netherlands Institute for Sea Research \& Utrecht University, Utrecht, The Netherlands \\ 5 Department of Estuarine and Delta Systems, NIOZ Royal Netherlands Institute for Sea Research \& Utrecht University, The Netherlands, Utrecht, The \\ Netherlands \\ 6 Department of Computational Geo-Ecology, Institute for Biodiversity and Ecosystem Dynamics, University of Amsterdam, Amsterdam, The Netherlands \\ 7 DESC (Dutch Experiment Support Center), Department of Oral and Maxillofacial Surgery / Oral Pathology, Vu University Medical Center \& Academic \\ Centre for Dentistry Amsterdam (ACTA) \& European Space Agency Technology Center (ESA-ESTEC), TEC-MMG LIS Lab, Noordwijk, Amsterdam, The \\ Netherlands \\ Corresponding Author: Martijn C Bart \\ Email address: m.c.bart@uva.nl
}

Successful dispersal of freshwater sponges depends on the formation of dormant sponge bodies (gemmules) under adverse conditions. Gemmule formation allows the sponge to overcome critical environmental conditions, for example desiccation or freezing, and to reestablish as a fully developed sponge when conditions are more favorable. A key process in sponge development from hatched gemmules is the construction of the silica skeleton. Silica spicules form the structural support for the three-dimensional filtration system the sponge uses to filter food particles from ambient water. We studied the effect of different hypergravity forces $(1,2.5,5,10$, and $20 \times g$ for $48 \mathrm{~h})$ - as measure for environmental stress - on the ability of developing sponges to set-up their spiculous skeleton. Additionally, we assessed whether the addition of nutrients (i.e. dissolved ${ }^{13} \mathrm{C}$ - and ${ }^{15} \mathrm{~N}$ labelled amino acids) compensates for this stress. Our results show that freshwater sponges can withstand prolonged periods of hypergravity exposure and successfully set-up their skeleton, even after $48 \mathrm{~h}$ under $20 \mathrm{x}$. Developing sponges were found to take up and assimilate dissolved food before forming a functional filtering system. However, fed and non-fed sponges showed no differences in skeleton formation and relative surface area growth, suggesting that the gemmules' intrinsic energy fulfills the processes of skeleton construction. Additionally, non-fed sponges formed oscula significantly more often than fed sponges, especially under higher $g$-forces. This suggests that the eventual formation of a filtration system might be stimulated by food deprivation and environmentally stressful conditions. These findings indicate that the process of spiculous 
skeleton formation is energy-efficient and highly resilient. The uptake of dissolved food substances by freshwater sponges may contribute to the cycling of dissolved organic matter (DOM) in freshwater ecosystems where sponges are abundant. 
1

2 Spiculous skeleton formation in the freshwater sponge Ephydatia fluviatilis
Title: under hypergravity conditions

\author{
Authors: \\ Martijn C. Bart ${ }^{1 *}$, Sebastiaan J. de Vet ${ }^{2,3}$, Didier M. de Bakker ${ }^{4,5}$, Brittany E. Alexander ${ }^{1}$, Dick \\ van Oevelen ${ }^{6}$, E. Emiel van Loon7, Jack J.W.A. van Loon ${ }^{8}$, Jasper M. de Goeij ${ }^{1}$ \\ ${ }^{1}$ Department of Freshwater and Marine Ecology, Institute for Biodiversity and Ecosystem Dynamics, \\ University of Amsterdam, Amsterdam, The Netherlands \\ ${ }^{2}$ Earth Surface Science, Institute for Biodiversity and Ecosystem Dynamics, University of Amsterdam, \\ Amsterdam, The Netherlands \\ ${ }^{3}$ Taxonomy \& Systematics, Naturalis Biodiversity Center, Leiden, The Netherlands \\ ${ }^{4}$ Microbiology \& Biogeochemistry, NIOZ Royal Netherlands Institute for Sea Research \& Utrecht \\ University, Utrecht, The Netherlands \\ ${ }^{5}$ Department of Estuarine and Delta Systems, NIOZ Royal Netherlands Institute for Sea Research \& \\ Utrecht University, The Netherlands, Utrecht, The Netherlands \\ ${ }^{6}$ Department of Computational Geo-Ecology, Institute for Biodiversity and Ecosystem Dynamics, \\ University of Amsterdam, Amsterdam, The Netherlands \\ ${ }^{7}$ Department of Computational Geo-Ecology, Institute for Biodiversity and Ecosystem Dynamics, \\ University of Amsterdam, Amsterdam, The Netherlands \\ ${ }^{8}$ DESC (Dutch Experiment Support Center), Department of Oral and Maxillofacial Surgery / Oral \\ Pathology, VU University Medical Center \& Academic Centre for Dentistry Amsterdam (ACTA) \&
}


24 European Space Agency Technology Center (ESA-ESTEC), TEC-MMG LIS Lab, Noordwijk, 25 Amsterdam, The Netherlands 
$26 *$ corresponding author, E-mail: m.c.bart@uva.nl

27

28 Running head: hypergravity skeleton formation freshwater sponge 
29 Abstract

30 Successful dispersal of freshwater sponges depends on the formation of dormant sponge bodies

31 (gemmules) under adverse conditions. Gemmule formation allows the sponge to overcome

32 critical environmental conditions, for example desiccation or freezing, and to re-establish as a

33 fully developed sponge when conditions are more favorable. A key process in sponge

34 development from hatched gemmules is the construction of the silica skeleton. Silica spicules

35 form the structural support for the three-dimensional filtration system the sponge uses to filter

36 food particles from ambient water. We studied the effect of different hypergravity forces $(1,2.5$,

375,10 , and $20 \times g$ for $48 \mathrm{~h}$ ) — as measure for environmental stress — on the ability of developing

38 sponges to set-up their spiculous skeleton. Additionally, we assessed whether the addition of

39 nutrients (i.e. dissolved ${ }^{13} \mathrm{C}$ - and ${ }^{15} \mathrm{~N}$-labelled amino acids) compensates for this stress. Our

40 results show that freshwater sponges can withstand prolonged periods of hypergravity exposure

41 and successfully set-up their skeleton, even after $48 \mathrm{~h}$ under $20 \mathrm{x} g$. Developing sponges were

42 found to take up and assimilate dissolved food before forming a functional filtering system.

43 However, fed and non-fed sponges showed no differences in skeleton formation and relative

44 surface area growth, suggesting that the gemmules' intrinsic energy fulfills the processes of

45 skeleton construction. Additionally, non-fed sponges formed oscula significantly more often than

46 fed sponges, especially under higher $g$-forces. This suggests that the eventual formation of a

47 filtration system might be stimulated by food deprivation and environmentally stressful

48 conditions. These findings indicate that the process of spiculous skeleton formation is energy-

49 efficient and highly resilient. The uptake of dissolved food substances by freshwater sponges

50 may contribute to the cycling of dissolved organic matter (DOM) in freshwater ecosystems

51 where sponges are abundant. 


\section{Introduction}

53 Sponges are among the oldest — more than 635 million years old — still existing metazoans on 54 Earth (Müller, 1998; Love et al., 2009). Due to its ancient heritage, the sponge body plan is 55 traditionally seen as the original blueprint for multi-cellularity (Müller, 2004; Nosenko et al., 56 2013). Although sponges lack organs, they possess a high level of functional complexity (Leys et 57 al., 2009; Srivastava et al., 2010). They have a well-developed food uptake and waste disposal 58 system constructed of numerous small inflow openings (ostia) and chambers containing filter cells (choanocytes) with actively beating flagella to create an internal water flow. Sponges can contract their ostia and water channels to modulate this water flow (Elliot \& Leys, 2007; Ludeman et al., 2014). After the indrawn water has passed the choanocyte chambers, waste products are discarded through excurrent canals (oscula). Sensory cilia inside the osculum use calcium channels to adapt the sponge' water filtering capacity, for example in response to temperature changes or increased suspended sediment (Ludeman et al., 2014; Cavalier-Smith, 65 2017).

67 species used in this study, is cosmopolitan and found throughout Earth's entire northern hemisphere (Van Soest et al. 2017). This shows the flexibility of this sponge to endure a wide range of environmental conditions. The colonization capacity of inland waters by freshwater sponges largely depends on the formation of small $(\sim 300 \mu \mathrm{m}$ diameter $)$ dormant sponge bodies (gemmules) under adverse conditions (Manconi \& Pronzato, 2008; Funayama, 2013). This form

72 of asexual reproduction allows the sponges to overcome critical environmental conditions (e.g.,

73 low water temperatures during wintertime or desiccation during hot summers) (Manconi \& 74 Pronzato, 2016). When conditions are more favorable, a fully-developed miniature sponge can 75 be re-established from a gemmule in approximately 1 week, depending on environmental 
76 conditions (Höhr, 1977; Ilan et al., 1996; Funayama et al., 2005) (Fig 1A). First, during

77 gemmule germination, totipotent stem cells contained within the gemmule differentiate into different cell types (Wierzejski 1915, 1935; Höhr, 1977). Secondly, during a process called

79 hatching, the cells within the gemmule migrate outwards while continuing to differentiate into

80

various cell types - including basal epithelial cells that attach the sponge to its substrate (Rozenfeld, 1970; Höhr, 1977; Harrison et al., 1981). Eventually, the migrated cells proliferate and differentiate into all types of cells to form a fully functional sponge (Höhr 1977; Funayama et al., 2005).

A key process in freshwater sponge development from hatched gemmules is the formation and construction of the skeleton. The sponge skeleton forms the structural support for the three-dimensional filtering system of the sponge (reviewed by Uriz et al., 2003). In demosponges, the skeleton consists of individualized elements (silica spicules), embedded in a fibrous organic matrix made from chitin and spongin (Larsen \& Riisgård, 1994; Uriz et al., 2003; Ehrlich et al., 2013). After the spicules are set in an upright position, the filter system of the sponge develops and the sponge can start to obtain nutrients by active filter-feeding (Funayama et al. 2005).

Recently, it was shown for E. fluviatilis that the silica spicules are not randomly distributed throughout the developing sponge body, but are deliberately set-up in a highlyorganized manner (Nakayama et al. 2010; 2015), similar to pitching a tent. Spicules are produced by cells termed sclerocytes, at various locations within the hatching gemmule, and transported by so-called transport cells to their final position, where they are erected and cemented by a third type of specialized cells (the basopinacocytes) (Nakayama et al. 2015). This division of labor between various cell types within the sponge has revealed a fundamentally new 
99

100

101

102

103

104

105

106

107

108

109

110

111

112

113

114

115

116

117

118

119

120

121

mechanism of constructing the three-dimensional body shape of animals (Nakayama et al., 2015). As stated by Nakayama et al., (2015), the spiculous skeleton construction process of $E$.

fluviatilis is the only known biological mechanism in which a sequence of cooperative behaviors of individual cells leads to the active construction of a self-organized biological structure using non-cellular materials. Moreover, the mediation of the different steps of spiculous skeleton construction by specialized cells allows for high plasticity and helps to generate the morphological diversity of fully-grown E. fluviatilis specimens.

Gemmule formation and hatching are seasonally dependent and it appears that external factors such as water temperature, water turbidity and illumination are responsible for these processes (Harsha et al., 1983; Ilan et al., 1996). However, at present it is unknown how most of these external factors affect the formation and hatching of gemmules. In addition, gemmule hatching and spicule body construction up to the moment of a fully-developed filter system is presumed to be mediated by internally-stored energy and therefore independent of externally available food sources. Archeocytes within the gemmules of fresh-water sponges are known to contain reserve substances including RNA, lipids and polysaccharides (Ruthmann, 1965). Hence, germination studies are usually performed in medium without added food sources (Funayama et al., 2005;Elliott \& Leys, 2007). This hypothesis is, however, never tested and therefore it is unknown whether developing sponges can obtain external energy sources before they have developed the capacity to actively filter-feed, and if this influences their development.

Access to the large diameter centrifuge (LDC) of the European space agency (ESA) in Noordwijk, the Netherlands, enabled us to test the influence of increased environmental stress (i.e. increased hypergravity ( $g$ ) forces) on the construction of the siliceous skeleton of developing sponges. Hypergravity is an artificially created condition in which the acceleration exceeds the 
122 common terrestrial gravitational acceleration of $9.81 \mathrm{~m} \mathrm{~s}^{-2}(1 \times \mathrm{g})$ and this creates a force

123 working directly against the sponge cells erecting the spicules. Furthermore, hypergravity has

124 been shown to alter the intracellular transport and delivery of cell wall material in plants (Chebli

125 et al., 2012), polyp growth in stony corals (Meroz et al., 2002) and effects skeletal architecture

126 and bone-repair in mammals (Prodanov et al., 2013; Canciani et al., 2015). Exposure to

127 hypergravity acts on the whole cell mass, and cells exposed to several g's can adapt by

128 decreasing the height of their microtubule network, but increasing the thickness of their actin

129 fibers without affecting cell viability (Kacena et al., 2004; Searby et al., 2005; van Loon et al., 130 2009).

131 We hypothesize that 1) increased $g$-forces decrease the ability of the sponge cells to 132 transport their spicules to their final location and to erect them due to the higher energy costs 133 involved, preventing the formation of a fully-developed filter system (e.g., no osculum 134 formation) and 2) that food addition will partially compensate for the expected energy shortage 135 caused by hypergravity (Fig. 1B).

137 To study the effects of external stress on skeleton formation in developing freshwater sponges, 138 we tested how prolonged exposure $(48 \mathrm{~h})$ to different hypergravity forces $(1,2.5,5,10$, and $20 \mathrm{x}$ $139 g$ ) influenced 1) relative surface area increase; i.e. the substrate area covered by basal epithelium 140 of the sponge compared to the area that was covered before the experiments commenced as 141 measure of growth, 2) the presence of a set-up skeleton and 3) the presence or absence of an 142 osculum in developing E. fluviatilis specimens hatched from gemmules. In addition, we tested 143 the ability of the developing sponges under above-mentioned conditions of hypergravity 
144 exposure to take up dissolved food (i.e. ${ }^{13} \mathrm{C}$ - and ${ }^{15} \mathrm{~N}$-enriched amino acids) and whether 145 additional feeding affects skeleton set-up and osculum formation. 


\section{Gemmule harvesting and preparation}

149 Gemmules were collected in the winter months (November 2013 to March 2014), from specimens of E. fluviatilis kept in outdoor aquaria at the University of Amsterdam. Sponge tissue containing the gemmules was collected and cleaned by rubbing the sponge tissue between two pieces of corduroy to free the gemmules from the sponge tissue scaffold that can inhibit germination. Detached gemmules were sterilized in $1 \% \mathrm{H}_{2} \mathrm{O}_{2}$ for $5 \mathrm{~min}$ on a shaker at $4^{\circ} \mathrm{C}$ to remove bacterial and fungal contaminants included in the coat (Funayama et al., 2005).

\section{Gemmule hatching}

A total of 420 gemmules from one individual sponge were plated on sterile 12-well culture plates in sterile M-Medium (Rasmont, 1961; $1 \mathrm{mM} \mathrm{CaCl}_{2}, 0.5 \mathrm{mM} \mathrm{MgSO} 4,0.5 \mathrm{mM} \mathrm{NaHCO} 3,0.05$ $\mathrm{mM} \mathrm{KCl}, 0.25 \mathrm{mM} \mathrm{Na} \mathrm{SiO}_{3}$ ) under ambient conditions. The plates were sealed by parafilm. Each well of the 12-well culture plates contained one gemmule in approximately $4 \mathrm{~mL}$ of $\mathrm{M}$ medium. After four days, before placing the gemmules in the LDC, the individuals that did not hatch were discarded and of the remaining hatched specimens, only the sponges in stage II were selected (i.e. specimens without any erected spicules or osculum, see Fig. 1A for a description of developmental stages). $72 \%$ of the plated gemmules hatched (302 out of 420 ), of which $n=277$ sponges developed to stage II that were subsequently used for the experiment in the LDC (Table accumulation of waste products in the well plates. 


\section{Sponge feeding with ${ }^{13} \mathrm{C}$ - and ${ }^{15} \mathrm{~N}$-enriched amino acids}

171 For each gravitational condition (see below), one group (i.e. approximately half) of the

172 gemmules was fed with isotopically-enriched $\left({ }^{13} \mathrm{C}\right.$ and $\left.{ }^{15} \mathrm{~N}\right)$ dissolved amino acids in order to 173 study nutrient uptake, whereas the other group remained unfed (Table 1). The fed groups $(n=$ $17422,20,25,29,26$, respectively for $1,2.5,5,10$, and $20 \mathrm{x} g$ ) were randomly selected and received 175 M-Medium with $390 \mu \mathrm{g} \mathrm{L}-1$ tracer ${ }^{13} \mathrm{C}-\left(11 \mu \mathrm{mol} \mathrm{L}^{-1}\right)$ and ${ }^{15} \mathrm{~N}-\left(2.2 \mu \mathrm{mol} \mathrm{L}^{-1}\right)$ enriched dissolved 176 amino-acids added prior to the LDC runs. The non-fed group $(n=24,21,21,19,20$, 177 respectively for $1,2.5,5,10$, and $20 \mathrm{x} g$ ) did was kept in sterile M-Medium throughout the 178 experiment.

\section{Hypergravity experiment in large diameter centrifuge}

181 Hypergravity experiments were performed using the large diameter centrifuge (LDC) of the European Space Agency (ESA, Noordwijk, The Netherlands) following a predetermined protocol (Fig. 2A). The LDC has a diameter of $8 \mathrm{~m}$ and comprehends four large arms fitted with outward swinging gondolas. The rotational movement of the arms creates an artificial acceleration field at the well plates positioned inside the gondolas, simulating different $g$-forces depending on gondola placement on the arms and rotational speed (Fig. 2B). Experiments where performed in two 48 -h runs. In the first 48 -h run developing sponges were exposed to 1 (i.e. as hypergravity control; placed at the center of the rotating LDC), 2.5 and $5 \mathrm{x} g$ and in the second run to 10 and $20 \mathrm{x} g$ (Fig. 2B). Per hypergravity level, both fed and non-fed sponges were tested simultaneously. To assess the effect of rotation on the development of the gemmules, a control 
193 between the first ( 2.5 and $5 \times g$ ) and the second run (10 and $20 \times g)$ no additional hypergravity

194 control at $1 \mathrm{x} g$ was performed during the second run.

195

196 Sponge surface area measurements

197 Before and after placement in the LDC, the surface area of the substrate covered by the sponges

198 (in $\mathrm{mm}^{2}$ ) was determined by light microscopy. We are aware that sponge volume is a better

199 metric for growth of sponges building a three-dimensional structure (i.e. the skeleton). However,

200 we were unable to accurately measure volume and therefore used the increase of substrate area

201 covered by the basal epithelium of the sponge relative to the substrate area covered by the basal

202 epithelium of the sponge before placement in the LDC, as a proxy for sponge size/growth. All

203 sponges were photographed and visually checked to assess substrate area cover, the set-up/no

204 set-up of the sponge skeleton, and the presence/absence of an osculum under a stereoscopic

205 microscope (Olympus SZH-ILLD with infinityl microscopy camera). Surface area measurements

206 were performed using Image J software (https://imagej.nih.gov/ij/).

207

208 Stable isotope analysis of sponges

209 After LDC exposure and microscopy imaging, the labeled M-medium was replaced with non-

210 labeled M-medium for $3 \times 5$ min to remove as much residual label as possible. After the last

211 replacement the sponges were left for $30 \mathrm{~min}$ in the non-labeled medium to remove any residual

212 label from the sponge surface. Subsequently, sponges were then taken out of the well-plates,

213 rinsed with M-medium and pooled per treatment, freeze-dried, homogenized, and stored at $-20^{\circ} \mathrm{C}$

214 in silver boats. Pooling was necessary to ensure that sufficient carbon and nitrogen was available

215 for the stable isotope analysis. Samples were put in silver boats, acidified with $5 \% \mathrm{HCl}$ to ensure 
216 removal of inorganic carbon, oven-dried at $60^{\circ} \mathrm{C}$, pinched closed and stored frozen before 217 analysis on an Elemental Analyser (EA, Firma Thermo Electron, Flash EA 1112 analyzer) that 218 was coupled to a Delta V isotope ratio mass spectrometer (IRMS) for simultaneous measurement 219 of ${ }^{13} \mathrm{C}:{ }^{12} \mathrm{C}$ and ${ }^{15} \mathrm{~N}:{ }^{14} \mathrm{~N}$ ratios. Reproducibility for the EA-IRMS analysis was $0.25 \%$ for ${ }^{15} \mathrm{~N}$ and $0.2 \%$ for ${ }^{13} \mathrm{C}$.

$222 \mathrm{~N}$ per mmol sponge $\mathrm{C}$ or $\mathrm{N}$ per $\mathrm{d}$. Rates are calculated from the delta notations obtained from the IRMS as $\delta \mathrm{X}(\%)=\left(\mathrm{R}_{\text {sample }} / \mathrm{R}_{\text {ref }}-1\right) \cdot 1000$, in which $\mathrm{X}$ is the element $(\mathrm{C}$ or $\mathrm{N}), \mathrm{R}_{\text {sample }}$ is the heavy : light isotope ratio in the sample and $\mathrm{R}_{\text {ref }}$ is the heavy : light isotope ratio in the reference material $\left(\mathrm{R}_{\mathrm{ref}}=0.0111797\right.$ for $\mathrm{C}$ and $\mathrm{R}_{\mathrm{ref}}=0.0036765$ for $\left.\mathrm{N}\right)$. The atomic fraction of the heavy isotope $(F)$ in a sample is calculated as $F=R_{\text {sample }} /\left(R_{\text {sample }}+1\right)$. The excess (above background) atomic fraction is the difference between the $\mathrm{F}$ in an experimental sample and the atomic fraction in a control (i.e. non-enriched) sample: $\mathrm{E}=\mathrm{F}_{\text {sample }}-\mathrm{F}_{\text {control }}$. The excess incorporation of ${ }^{13} \mathrm{C}$ and ${ }^{15} \mathrm{~N}$ was multiplied by 1,000 to express rates in $\mu$ mol tracer $\mathrm{C}$ or $\mathrm{N}$ per mmol sponge $\mathrm{C}$ or $\mathrm{N}$ and divided by the incubation time to convert to daily rates.

\section{Statistical analysis}

233 To analyze the effect of rotation without hypergravity exposure on the sponges, a two sample ttest was performed to compare the means of the two (rotating/non-rotating) $1 \mathrm{x} g$ groups. A chisquare test was used to compare osculum development between the two groups. Both tests were 
Surface area cover increase is expressed as a percentage relative to the original surface 239 are covered by each developing sponge hatched from a gemmule in stage II at the start of the 240 LDC experiment. The effect of hypergravity on percentage surface increase was investigated by 241 a linear model, adopting a 0.05 significance level. Besides evaluation of the overall model 242 significance, also the pairwise differences among the treatment-levels were made through a 243 Tukey HSD test with a 95\% family-wise confidence level.

244 Osculum formation was analyzed with a generalized linear model using a binomial error 245 function. To address the effect of osculum formation and $g$-force on the mean dissolved organic 246 matter uptake (measured by ${ }^{13} \mathrm{C}$ and ${ }^{15} \mathrm{~N}$ enrichment), an additive linear model was evaluated, 247 using a 0.05 significance level.

248 In the results, means and proportions are reported in combination with the standard 249 deviation between brackets. All analyses were carried out in Rstatistics programming 250 environmentR 3.3.2(The R Foundation for Statistical Computing, 2004-2013). 


\section{Results}

252

\section{Sponge development under hypergravity exposure}

254 The non-rotating and rotating controls at $1 \times \mathrm{x}$ did not show a significant difference in sponge 255 growth (two-sample $t$-test, $t(31)=-0.341, p>0.1$ ), skeleton formation (in both groups $100 \%$ of 256 the sponge specimens showed set up skeleton) or osculum development (chi square test, $\chi^{2}(2, n$ $257=33)=1.8397, p>0.1)$.

Over all levels of (hyper)gravity exposure, 96\% $( \pm 1 \%)$ of stage II juvenile sponges developed to stage III juvenile sponges (i.e. with erected skeleton), 66\% ( $\pm 7 \%$ ) of all sponges reached stage IV, (i.e. build an osculum) and formed a fully functional sponge during their 48-h treatment (Table 1). All sponges showed an increase in surface area of on average $196 \%( \pm 70 \%)$ compared with the surface area before placement in the LDC. However, the increase in surface area significantly decreased at higher hypergravity levels $(\mathrm{R} 2=0.07, n=227, p<0.01)$ (Fig. 3 panel A, Fig. 4). Comparing the different treatment levels (using a Tukey HSD test), only the relative surface area change between 1 versus $20 \times g(-47 \%, \mathrm{p}<0.01)$ and 5 versus $20 \times g(-45 \%$, $\mathrm{p}<0.01)$ were significant.

No effect of feeding on surface area increase was found (Fig. 4). A significant interaction

effect of $g$-force and feeding on mean osculum formation per group was observed, where fed sponges formed oscula less frequently than non-fed sponges, especially at higher $g$-force $(\operatorname{logit}($ osculum formation $)=0.71-0.13 \cdot$ feeding $+0.06 \cdot g$-force $-0.10 \cdot$ feeding $\cdot g$-force;

271 Nagelkerke- $\left.\mathrm{R}^{2}=0.08, n=227, p<0.05\right)$.

\section{Tracer isotope incorporation}


274 Amino acid assimilation was confirmed by significant enrichment in both $\delta^{13} \mathrm{C}(42.5 \pm 11.1 \%$ )

275 and $\delta^{15} \mathrm{~N}(1202.8 \pm 280.2 \%$ o $)$ in the tissues of all fed sponges compared with background, non-

276 fed, sponge tissue $\left(-30.5 \% \delta^{13} \mathrm{C}\right.$ and $\left.18.2 \% \delta^{15} \mathrm{~N}\right)$. On average, hatching E. fluviatilis assimilated

$2770.4 \pm 0.1 \mu \mathrm{mol} \mathrm{C}_{\text {amino acids }} \mathrm{mmol} \mathrm{C}_{\text {sponge }}{ }^{-1} \mathrm{~d}^{-1}$ and $4.3 \pm 1.0 \mu \mathrm{mol} \mathrm{N}$ amino acids $\mathrm{mmol} \mathrm{N}_{\text {sponge }}{ }^{-1} \mathrm{~d}^{-1}$

278 (Fig. 5). In total, $9.1 \pm 3.7 \%$ and $41.2 \pm 18.5 \%$ of the added amino acid carbon and nitrogen,

279 respectively, was processed by the sponges during the 48-h incubations. No significant effect of

$280 g$-force was found on ${ }^{13} \mathrm{C}$-assimilation rates, while the overall effect for ${ }^{15} \mathrm{~N}$ assimilation rates

281 was significant ( $\mathrm{C} \sim g$-force, $n=10, p=0.165$; $\mathrm{N} \sim g$-force, $n=10, p<0.05$ ) (Fig. 5). When

282 comparing the effects on ${ }^{15} \mathrm{~N}$ for different treatment levels (using a Tukey HSD test), only the

283 difference between 5 x $g$ versus $20 \times g(-2.7, p<0.01)$ appeared significant. 


\section{Discussion}

\section{Spiculous skeleton construction and osculum formation under hypergravity}

286 Sponges are known for their enormous plasticity and opportunistic nature when it comes to food

287 selection (e.g., Ribes et al. 1999; McMurray et al. 2016) and regeneration after environmental

288 stress (e.g., Ayling et al. 1983; Wulff 2010; Alexander et al. 2015). This is particularly important

289 in ecosystems with large seasonal fluctuations in water temperature and food availability, where

290 the formation of gemmules by freshwater sponges is a very successful strategy to survive these

291 adverse and possibly lethal conditions. When conditions are more favorable, gemmules hatch

292 and develop into fully grown sponges in order to enter a successful sexual reproductive stage and

293 obtain sufficient biomass to gemmulate (Funayama et al., 2005; Manconi \& Pronzato, 2016).

294 The formation of the spiculous skeleton is a crucial feature of the morphogenesis of freshwater

295 sponges, resulting eventually in the formation of an active filter-feeding system (Rozenfeld,

296 1980; Funayama et al., 2005), enabling the sponge to grow and reproduce. Albeit the

297 hypergravity forces used in our experiment are not naturally occurring, this is the first in vivo

298 study of freshwater sponges to show that skeleton formation of E. fluviatilis is highly resilient

299 under high levels of stress. Even after the juvenile sponges were exposed to hypergravity forces

300 up to $20 \mathrm{xg}$ for $48 \mathrm{~h}$, they managed to survive, grow, create and organize their spicules, and

301 develop a functional food-uptake system. In comparison, a well-trained human astronaut has a $g$ -

302 force tolerance of approximately $9 \times \mathrm{x} g$ for only short periods of seconds to minutes (Wu et al.,

303 2012). Our initial hypothesis that increased $g$-forces decrease the ability of the sponge cells to

304 transport and erect their spicules and prevent the formation of a fully-developed filter system

305 (e.g., no osculum formation) is clearly rejected. Sponges showed a significantly smaller increase

306 of substrate area covered at higher $g$-force, which may suggest impaired growth, but almost all 
307 specimens $(96 \pm 1 \%)$ were able to set-up their spiculous skeleton and the majority was able to 308 create and osculum $(66 \pm 7 \%)$.

309 It is noteworthy that, although this study focused on the siliceous spicules of the $E$.

310 fluviatilis skeleton, the fibrous matrix of spongin and possibly chitin in which the spicules are

311 embedded, may also play a role in withstanding environmental stress (Ehrlich et al., 2010, 2013).

312 The presence of chitin is known to be responsible for the rigidification or skeletal structures in 313 invertebrates including marine demosponges (Brunner et al., 2009; Ehrlich et al., 2010) and has

314 since long been known to be an important component of E. fluviatilis gemmules (Zykoff, 1892).

315 However, the presence of chitin has not been reported in adult specimens of E. fluviatilis and it is 316 at present unknown whether or how the fibrous matrix of the skeleton changes in response to 317 environmental conditions.

319 Fed versus non-fed sponges under hypergravity

320 We also show that hatching E. fluviatilis can take up dissolved nutrients (i.e. amino acids).

321 Previous evidence corroborates that freshwater sponges can feed on dissolved organic food 322 sources, such as dissolved proteins (Weissenfels, 1976; Manconi \& Pronzato, 2008). However, 323 this study shows, for the first time, that developing sponges hatched from gemmules take up and 324 incorporate dissolved food sources in their tissue possibly even before arranging their filter 325 system and start active pumping. In that case, the dissolved ${ }^{13} \mathrm{C}$ - and ${ }^{15} \mathrm{~N}$-labeled amino acids can 326 be acquired either via passive diffusion or through phagocytosis by choanocytes or surface 327 pinacocytes (Willenz \& van de Vyver, 1982; Smith \& Tiffon, 2013). However, the uptake of 328 dissolved amino acids did not affect skeleton formation nor surface area growth. We therefore 329 conclude that the added nutrients are not a necessity for the developing sponges to overcome the 
330

331

332

333

334

335

336

337

338

339

340

341

342

343

344

345

346

347

348

349

350

351

352

environmental stress caused by hypergravity. Since most of the sponges developed normally even under extreme levels of stress, this suggests that the process of erecting the spiculous skeleton relies mainly on intrinsic energy contained within the gemmule. Interestingly, fed sponges developed oscula significantly less frequently compared with non-fed sponges, especially at exposure to the highest (10 and $20 \mathrm{x}) \mathrm{g}$-forces. We speculate that under extremely stressful conditions, when energy costs are highest, sponges invest in the formation of an active filtration system to acquire new energy. Additional food can help prolong the process of hatching and skeleton development, which might increase their chances of survival throughout severe stress conditions.

\section{The role of dissolved food in the diet of freshwater sponges}

The capacity of developing E. fluviatilis to readily take up dissolved food sources could be a valuable addition to the daily natural diet of adult stages of the sponge. Evidence is accumulating that many sponge species utilize dissolved organic matter (DOM) as major part (71-94\%) of their daily carbon intake (Yahel et al. 2003; De Goeij et al. 2008; Mueller et al. 2014; McMurray et al., 2016), however, these studies were all done on marine sponge species.

The uptake of DOM is hypothesized to be influenced by the presence of associated microbes. It has been shown that mainly sponges with high numbers of associated bacteria (high microbial abundance (HMA) sponges) utilize DOM as food source, as opposed to the low microbial abundance (LMA) sponges (Hoer et al. 2018), unless sponges have an encrusting growth form (De Goeij et al. 2017). The freshwater sponge E. fluviatilis is a LMA species, but the algal symbionts of E. fluviatilis are not an obligate requirement for survival of the host (Wilkinson, 1980). Moreover, E. fluviatilis can be both encrusting and massive, depending on its stage of 
353 development. In this study, we cannot conclude on the role of associated microbes in the

354 processing of DOM. Although all gemmules were sterilized before the experiment, the presence

355 of associated microbes in the sponge specimens cannot be excluded. Moreover, by determining

356 bulk assimilation of the isotope tracer we cannot distinguish whether DOM was processed by

357 symbionts or occurred directly be sponge cells. Future studies using bacterial-and sponge-

358 specific fatty acid biomarkers (e.g., de Goeij et al. 2008b, Rix et al. 2017) may identify these

359 processes. It would be interesting to assess whether E. fluviatilis adjusts its diet depending on its

360 algal symbionts and/or at various phases of its life-cycle.

361

362 In tropical coral reefs, sponges play a key role in the cycling of nutrients by converting

363 predominantly DOM into particulate organic matter (POM) through high cell turnover and

364 detritus production, which is subsequently shunted to higher trophic levels - a process termed the

365 sponge loop (de Goeij et al., 2013). Since detritus production and rapid division of choanocytes

366 by mitosis have been reported for E. fluviatilis (Weissenfels, 1976; Tanaka \& Watanabe, 1984),

367 similar sponge-loop processes potentially also occur in freshwater systems. Additionally, the

$368 \mathrm{C}: \mathrm{N}$ ratio of the amino acids (5:1) in the medium was significantly lower than the assimilated

369 C:N ratio by E. fluviatilis (1:5), and the sponge assimilated up to 4 times more nitrogen from the

370 amino acids (41\%) as compared with amino acid carbon (9\%). Carbon could have been partly

371 lost to respiration, but E. fluviatilis most likely assimilated nitrogen selectively from the amino

372 acid source. As sponge detritus in eutrophic tropical ecosystems was found relatively enriched in

373 nitrogen compared to sponge tissue (de Goeij et al., 2013), and the current view is that limitation

374 of nitrogen is also common in eutrophic freshwaters (Downing \& McCauley, 1992), freshwater 
375 sponges might fertilize their surrounding ecosystems in the same way as their marine 376 counterparts.

377

\section{Conclusions}

379 Our results demonstrate that the process of skeleton formation in freshwater sponges is highly 380 resilient, coping with extreme $g$-forces of up to $20 \mathrm{x} g$ for as long as two days. These results also 381 support the ideas of Nakayama et al. (2015) that the mechanisms of self-construction shown by 382 E. fluviatilis are adjusted by its (micro)environment and are potentially useful in other fields of 383 research such as (bio)engineering. The underlying cellular and molecular mechanisms of 384 processes such as spicule displacement, arrangement and cementing as well as their adaptive 385 potential are at present unknown. In addition, this study supports the findings of Skelton \& 386 Strand (2013) that freshwater sponges may serve as an important energetic link between pelagic 387 and benthic food webs in systems were sponges are abundant. The uptake of dissolved food may 388 be an important factor in the daily diet of freshwater sponges and they may contribute 389 significantly to the cycling of dissolved nutrients in freshwater ecosystems. 
390

391

392

393

394

395

396

397

398

399

400

401

402

403

404

405

406

407

408

409

410

411

412

\section{References}

Alexander, B. E., Achlatis, M., Osinga, R., van der Geest, H. G., Cleutjens, J. P., Schutte, B., \& de Goeij, J. M. (2015). Cell kinetics during regeneration in the sponge Halisarca caerulea: how local is the response to tissue damage?. PeerJ, 3, e820.

Ayling, A. L. (1983). Growth and regeneration rates in thinly encrusting demospongiae from temperate waters. The Biological Bulletin, 165(2), 343-352.

Brunner, E., Ehrlich, H., Schupp, P., Hedrich, R., Hunoldt, S., Kammer, M., ... \& Arnold, T. (2009). Chitin-based scaffolds are an integral part of the skeleton of the marine demosponge Ianthella basta. Journal of structural biology, 168(3), 539-547.

Canciani, B., Ruggiu, A., Giuliani, A., Panetta, D., Marozzi, K., Tripodi, M., ... \& Tavella, S. (2015). Effects of long time exposure to simulated micro-and hypergravity on skeletal architecture. Journal of the mechanical behavior of biomedical materials, 51, 1-12.

Cavalier-Smith, T. (2017). Origin of animal multicellularity: precursors, causes, consequencesthe choanoflagellate/sponge transition, neurogenesis and the Cambrian explosion. Philosophical Transaction of the Royal Society of Biological Sciences, 372(1713), 20150476.

Chebli, Y., Van Loon, J., \& Geitmann, A. N. J. A. (2012). Live cell imaging under hyper-gravity conditions. Bulletin microscopical society canada, 40(3), 8-12.

De Goeij, J. M., van den Berg, H., van Oostveen, M. M., Epping, E. H., \& Van Duyl, F. C. (2008a). Major bulk dissolved organic carbon (DOC) removal by encrusting coral reef cavity sponges. Marine Ecology Progress Series, 357, 139-151.

De Goeij, J. M., Moodley, L., Houtekamer, M., Carballeira, N. M., \& Van Duyl, F. C. (2008b). Tracing 13C-enriched dissolved and particulate organic carbon in the bacteria-containing 
413

414

415

416

417

418

419

420

421

422

423

424

425

426

427

428

429

430

431

432

433

coral reef sponge Halisarca caerulea: Evidence for DOM-feeding. Limnology and Oceanography, 53(4), 1376-1386.

De Goeij, J. M., Van Oevelen, D., Vermeij, M. J., Osinga, R., Middelburg, J. J., de Goeij, A. F., \& Admiraal, W. (2013). Surviving in a marine desert: the sponge loop retains resources within coral reefs. Science, 342(6154), 108-110.

De Goeij, J. M., Lesser, M. P., \& Pawlik, J. R. (2017). Nutrient Fluxes and Ecological Functions of Coral Reef Sponges in a Changing Ocean. In Climate Change, Ocean Acidification and Sponges (pp. 373-410). Springer, Cham.

Downing, J. A., \& McCauley, E. (1992). The nitrogen: phosphorus relationship in lakes. Limnology and Oceanography, 37(5), 936-945.

Ehrlich, H., Ilan, M., Maldonado, M., Muricy, G., Bavestrello, G., Kljajic, Z., ... \& Born, R. (2010). Three-dimensional chitin-based scaffolds from Verongida sponges (Demospongiae: Porifera). Part I. Isolation and identification of chitin. International Journal of Biological Macromolecules, 47(2), 132-140.

Ehrlich, H., Kaluzhnaya, O. V., Brunner, E., Tsurkan, M. V., Ereskovsky, A., Ilan, M., ... \& Born, R. (2013). Identification and first insights into the structure and biosynthesis of chitin from the freshwater sponge Spongilla lacustris. Journal of Structural Biology, 183(3), 474-483.

Elliott, G. R., \& Leys, S. P. (2007). Coordinated contractions effectively expel water from the aquiferous system of a freshwater sponge. Journal of Experimental Biology, 210(21), 3736-3748. 
434 Funayama, N., Nakatsukasa, M., Hayashi, T., \& Agata, K. (2005). Isolation of the choanocyte in 435 the fresh water sponge, Ephydatia fluviatilis and its lineage marker, Ef 436 annexin. Development, growth \& differentiation, 47(4), 243-253.

437 Funayama, N. (2013). The stem cell system in demosponges: suggested involvement of two

438

439

440

441

442

443

444

445

446

447

448

449

450

451

452

453

454

455

456 types of cells: archeocytes (active stem cells) and choanocytes (food-entrapping flagellated cells). Development genes and evolution, 223(1-2), 23-38.

Harrison, F. W., Rosenberg, E. M., Davis, D. A., \& Simpson, T. L. (1981). Correlation of cyclic GMP and cyclic AMP immunofluorescence with cytochemical patterns during dormancy release and development from gemmules in Spongilla lacustris L.(Porifera: Spongillidae). Journal of Morphology, 167(1), 53-63.

Harsha, R. E., Francis, J. C., \& Poirrier, M. A. (1983). Water temperature: a factor in the seasonality of two freshwater sponge species, Ephydatia fluviatilis and Spongilla alba. Hydrobiologia, 102(3), 145-150.

Hoer, D. R., Gibson, P. J., Tommerdahl, J. P., Lindquist, N. L., \& Martens, C. S. (2018). Consumption of dissolved organic carbon by Caribbean reef sponges. Limnology and Oceanography.

Höhr, D. (1977). Differenzierungsvorgänge in der keimenden Gemmula vonEphydatia fluviatilis. Wilhelm Roux's archives of developmental biology, 182(4), 329-346.

Ilan, M., Dembo, G., \& Gasith, A. (1996). Gemmules of sponges from a warm lake. Freshwater Biology, 35(1), 165-172.

Kacena, M. A., Todd, P., Gerstenfeld, L. C., \& Landis, W. J. (2004). Experiments with osteoblasts cultured under hypergravity conditions. Microgravity-Science and Technology, 15(1), 28. 
457 Larsen, P. S., \& Riisgård, H. U. (1994). The sponge pump. Journal of Theoretical Biology, $458 \quad 168(1), 53-63$.

459 Leys, S. P., Nichols, S. A., \& Adams, E. D. (2009). Epithelia and integration in $460 \quad$ sponges. Integrative and Comparative Biology, 49(2), 167-177.

461 Love, G. D., Grosjean, E., Stalvies, C., Fike, D. A., Grotzinger, J. P., Bradley, A. S., ... \& 462 Bowring, S. A. (2009). Fossil steroids record the appearance of Demospongiae during the $463 \quad$ Cryogenian period. Nature, 457(7230), 718-721.

464 Ludeman, D. A., Farrar, N., Riesgo, A., Paps, J., \& Leys, S. P. (2014). Evolutionary origins of 465 sensation in metazoans: functional evidence for a new sensory organ in sponges. $B M C$ evolutionary biology, 14(1), 3.

467

468

469

470

471

472

473

474

475

476

477

478

479

Manconi, R., \& Pronzato, R. (2008). Global diversity of sponges (Porifera: Spongillina) in freshwater. Hydrobiologia, 595(1), 27-33.

Manconi, R., \& Pronzato, R. (2016). How to survive and persist in temporary freshwater? Adaptive traits of sponges (Porifera: Spongillida): A review. Hydrobiologia, 782(1), 1122.

McMurray, S. E., Johnson, Z. I., Hunt, D. E., Pawlik, J. R., \& Finelli, C. M. (2016). Selective feeding by the giant barrel sponge enhances foraging efficiency. Limnology and Oceanography, 61(4), 1271-1286.

Meroz, E., Brickner, I., Loya, Y., Peretzman-Shemer, A., \& Ilan, M. (2002). The effect of gravity on coral morphology. Proceedings of the Royal Society of London B: Biological Sciences, 269(1492), 717-720.

Mohri, K., Nakatsukasa, M., Masuda, Y., Agata, K., \& Funayama, N. (2008). Toward understanding the morphogenesis of siliceous spicules in freshwater sponge: Differential 
mRNA expression of spicule-type-specific silicatein genes in Ephydatia fluviatilis. Developmental Dynamics, 237(10), 3024-3039.

Mueller, B., de Goeij, J. M., Vermeij, M. J., Mulders, Y., van der Ent, E., Ribes, M., \& van Duyl, F. C. (2014). Natural diet of coral-excavating sponges consists mainly of dissolved organic carbon (DOC). PloS one, 9(2), e90152.

Müller, W.E.G. (1998). Origin of Metazoa: sponges as living fossils. Naturwissenschaften, 85(1), 11-25.

Müller, W. E., Wiens, M., Adell, T., Gamulin, V., Schröder, H. C., \& Müller, I. M. (2004). Bauplan of urmetazoa: basis for genetic complexity of metazoa. International review of cytology, 235, 53-92.

Nakayama S, Arima, K., Mohri,K., \& Funayama, N. (2010). Spiculous skeleton formation as a new model to clarify pattern formation in demosponges: The roughly spaced spicule holding up (SHU) points and the identification of spicule carrying cells. Proceedings of 8th World Sponge Symposium, Girona, Spain, 86.

Nakayama, S., Arima, K., Kawai, K., Mohri, K., Inui, C., Sugano, W., ... \& Arai-Shindo, M. (2015). Dynamic transport and cementation of skeletal elements build up the pole-andbeam structured skeleton of sponges. Current Biology, 25(19), 2549-2554.

Nosenko, T., Schreiber, F., Adamska, M., Adamski, M., Eitel, M., Hammel, J., ... \& Vacelet, J. (2013). Deep metazoan phylogeny: when different genes tell different stories. Molecular phylogenetics and evolution, 67(1), 223-233.

Prodanov, L., Semeins, C. M., van Loon, J. J. W. A., Te Riet, J., Jansen, J. A., Klein-Nulend, J., \& Walboomers, X. F. (2013). Influence of nanostructural environment and fluid flow on 
502

503

504

505

506

507

508

509

510

511

512

513

514

515

516

517

518

519

520

521

522

523

524

osteoblast-like cell behavior: a model for cell-mechanics studies. Acta biomaterialia, 9(5), 6653-6662.

Rasmont, R. (1961). Une technique de culture des éponges d'eau douce en milieu contrôlé. Ann. Soc. R. Zool. Belg, 91, 147-155.

Ribes, M., Coma, R., \& Gili, J. M. (1999). Natural diet and grazing rate of the temperate sponge Dysidea avara (Demospongiae, Dendroceratida) throughout an annual cycle. Marine Ecology Progress Series, 179-190.

Rix, L., de Goeij, J. M., van Oevelen, D., Struck, U., Al-Horani, F. A., Wild, C., \& Naumann, M. S. (2017). Differential recycling of coral and algal dissolved organic matter via the sponge loop. Functional Ecology, 31(3), 778-789.

Rozenfeld, F. (1970). Inhibition du développement des gemmules de spongillides: spécificité et moment d'action de la gemmulostasine. Archives de Biologie Liege, 81, 193-214.

Rozenfeld, F. (1980). Effects of puromycin on the differentiation of the freshwater sponge: Ephydatia fluviatilis. Differentiation, 17(1-3), 193-198.

Ruthmann, A. (1965). The fine structure of RNA-storing archaeocytes from gemmules of freshwater sponges. Journal of Cell Science, 3(73), 99-114.

Searby, N. D., Steele, C. R., \& Globus, R. K. (2005). Influence of increased mechanical loading by hypergravity on the microtubule cytoskeleton and prostaglandin E2 release in primary osteoblasts. American Journal of Physiology-Cell Physiology, 289(1), C148-C158.

Skelton, J., \& Strand, M. (2013). Trophic ecology of a freshwater sponge (Spongilla lacustris) revealed by stable isotope analysis. Hydrobiologia, 709(1), 227-235.

Smith, D. C., \& Tiffon, Y. (Eds.). (2013). Nutrition in the Lower Metazoa: Proceedings of a Meeting Held at the University of Caen, France, 11-13 September 1979. Elsevier. 
525 Srivastava, M., Simakov, O., Chapman, J., Fahey, B., Gauthier, M. E., Mitros, T., ... \& Larroux,

526

527

528

529

530

531

532

533

534

535

536

537

538

539

540

541

542

543

544

545

546

547
C. (2010). The Amphimedon queenslandica genome and the evolution of animal complexity. Nature, 466(7307), 720-726.

Tanaka, K., \& Watanabe, Y. (1984). Choanocyte differentiation and morphogenesis of choanocyte chambers in the fresh-water sponge, Ephydatia fluviatilis, after reversal of developmental arrest caused by hydroxyurea. Zoological science, 1(4), p561-570.

Uriz, M. J., Turon, X., Becerro, M. A., \& Agell, G. (2003). Siliceous spicules and skeleton frameworks in sponges: origin, diversity, ultrastructural patterns, and biological functions. Microscopy research and technique, 62(4), 279-299.

Van Loon, J. J. W. A., Van Laar, M. C., Korterik, J. P., Segerink, F. B., Wubbels, R. J., De Jong, H. A. A., \& Van Hulst, N. F. (2009). An atomic force microscope operating at hypergravity for in situ measurement of cellular mechano-response. Journal of microscopy, 233(2), 234-243.

Van Soest, R.W.M., Boury-Esnault, N., Hooper, J.N.A., Rützler, K., de Voogd, N.J., Alvarez de Glasby, B., Hajdu, E., Pisera, A.B., Manconi, R., Schoenberg, C., Klautau, M., Picton, B., Kelly, M., Vacelet, J., Dohrmann, M., Díaz, M.-C., Cárdenas, P., Carballo, J. L., \& Rios Lopez, P. (2017). World Porifera database. (Accessed at 1-10-2018).

Weissenfels, N. (1976). Bau und Function des Susswasser-schwamms Ephydatia fluviatilis L.(Porifera) III. Nahrung-saufnahme, Verdauung und Defakation. Zoomorphologie, 85, $73-88$.

Wierzejski, A. (1915). Beobachtungen über die Entwicklung der Gemmulae der Spongilliden und des Schwammes aus den Gemmulis. Bulletin International De l'Academie Polonaise Des Sciences Et Des Lettre (B), 2, 45-79. 
548 Wierzejski, A. (1935). Süsswasserspongilliden: Monographische Bearbeitung. Mémoires $549 \quad$ Academy Polony (B) 9, 1-242

550 Wilkinson, C. R. (1980). Nutrient translocation from green algal symbionts to the freshwater 551 sponge Ephydatia fluviatilis. Hydrobiologia, 75(3), 241-250.

552 Willenz, P., \& Van De Vyver, G. (1982). Endocytosis of latex beads by the exopinacoderm in 553 the fresh water sponge Ephydatia fluviatilis: an in vitro and in situ study in SEM and 554 TEM. Journal of ultrastructure research, 79(3), 294-306.

555 Wu, B., Xue, Y., Wu, P., Gu, Z., Wang, Y., \& Jing, X. (2012). Physiological responses of 556 astronaut candidates to simulated+ Gx orbital emergency re-entry. Aviation, space, and environmental medicine, 83(8), 758-763.

558 Wulff, J. (2010). Regeneration of sponges in ecological context: is regeneration an integral part 559 of life history and morphological strategies?. Integrative and Comparative Biology, 50(4), 494-505.

561

562

Yahel, G., Sharp, J.H., Marie, D., Hase, C., \& Genin, A. (2003). In situ feeding and element

563 removal in the symbiont-bearing sponge Theonella swinhoei: Bulk DOC is the major source for carbon. Limnology and Oceanography 48:141-149

564

Zykoff, W. (1892). The development of the gemmules of Ephydatia fluviatilis, Auct. Journal of 565 Natural History, 10(59), 413-415. 


\section{Table $\mathbf{1}$ (on next page)}

Development of $E$. fluviatilis gemmules under hypergravity exposure $\left(1 \times g=9.81 \mathrm{~m} \mathrm{~s}^{-2}\right)$

Table 1. Development of $E$. fluviatilis gemmules under hypergravity exposure $(1 \times g=9.81 \mathrm{~m}$

$\mathrm{s}^{-2}$ ). Stage III sponges have erected silica spicules. Stage IV sponges have erected silica spicules and developed an osculum. 


\begin{tabular}{|c|c|c|c|c|c|c|c|c|c|c|c|c|c|}
\hline$g$-force & \multicolumn{2}{|c|}{1} & \multicolumn{2}{|c|}{2.5} & \multicolumn{2}{|c|}{5} & \multicolumn{2}{|c|}{10} & \multicolumn{2}{|c|}{20} & Total & non-fed & fed \\
\hline Fed & No & Yes & No & Yes & No & Yes & No & Yes & No & Yes & \multirow{2}{*}{227} & \multirow{2}{*}{122} & \multirow{2}{*}{105} \\
\hline$n$ & 24 & 22 & 21 & 20 & 21 & 25 & 19 & 29 & 20 & 26 & & & \\
\hline $\begin{array}{c}\text { Stage III } \\
\text { reached } \\
(\%)\end{array}$ & 100 & 95 & 100 & 90 & 95 & 92 & 100 & 93 & 100 & 96 & $\begin{array}{c}96 \% \\
( \pm 1 \%)\end{array}$ & $\begin{array}{c}\mathbf{9 9 \%} \\
( \pm 1 \%)\end{array}$ & $\begin{array}{c}\mathbf{9 3 \%} \\
( \pm 1 \%)\end{array}$ \\
\hline $\begin{array}{c}\text { Stage IV } \\
\text { reached } \\
(\%)\end{array}$ & 79 & 73 & 95 & 60 & 29 & 48 & 79 & 59 & 95 & 46 & $\begin{array}{c}\mathbf{6 6 \%} \\
( \pm 7 \%)\end{array}$ & $\begin{array}{c}\mathbf{7 5 \%} \\
( \pm 13 \%)\end{array}$ & $\begin{array}{c}\mathbf{5 7 \%} \\
( \pm 5 \%)\end{array}$ \\
\hline
\end{tabular}

1

2

3

4

5

6

7

8

9

10

11

12

13

14

15

16

17

18

19

20

21

22

23

24

25

26

27

28

29

30

31

32

33

34

35

36

37

38

39

40

41

42 


\section{Figure 1}

Fig. 1. Developmental stages of germination in the freshwater sponge Ephydatia fluviatilis \& hypothetical working model of the effect of hypergravity and nutrient uptake on skeleton construction of a juvenile sponge.

(A) modified from Funayama et al. (2005). Stage 0: resting gemmule. Stage I: (approximately 2-d post-hatching): cells migrate outwards from the gemmule and differentiate into epithelial cells. Stage II: (3-4 d): cells start to proliferate and begin to differentiate into different cell types. This stage includes the development of the spicule-making sclerocytes. Spicule production generally starts around stage II and continues thereafter (Funayama et al., 2005; Mohri et al., 2008). Stage III: (4-5 d post-hatching): the canal system and choanocyte chambers are starting to form. Stage IV: (6-7 d post-hatching): The osculum is created approximately one week after hatching, creating a fully functional sponge. (B) Hypothesized response of the influence of hypergravity on developing sponges in combination with feeding. We hypothesize sponges will not be able to set up their spicule skeleton after prolonged exposure to increasing levels of hypergravity, but counteract this inability after additional feeding on dissolved food sources before forming a fully functional active filterfeeding system. 

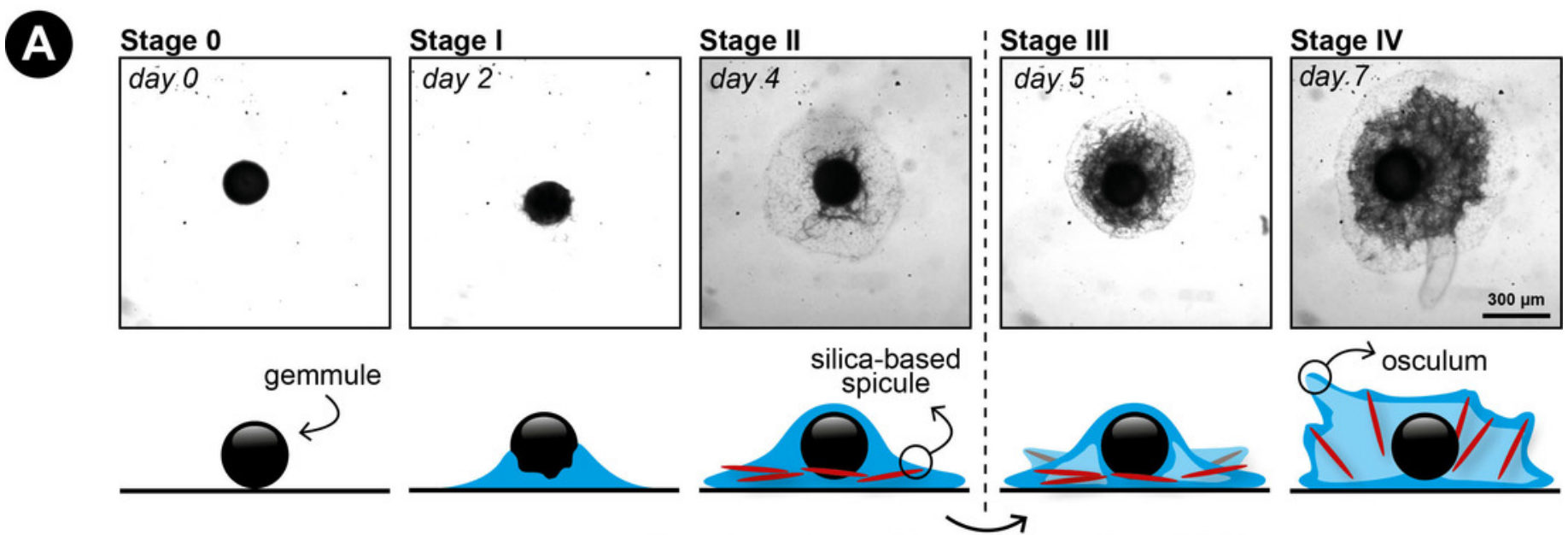

Transfer to Large Diameter Centrifuge (LDC)

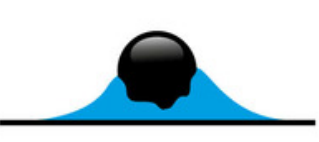

\section{B Acceleration LDC}

Hypothesised sponge growth in response to increasing g-force

Final configuration with no additional nutrients
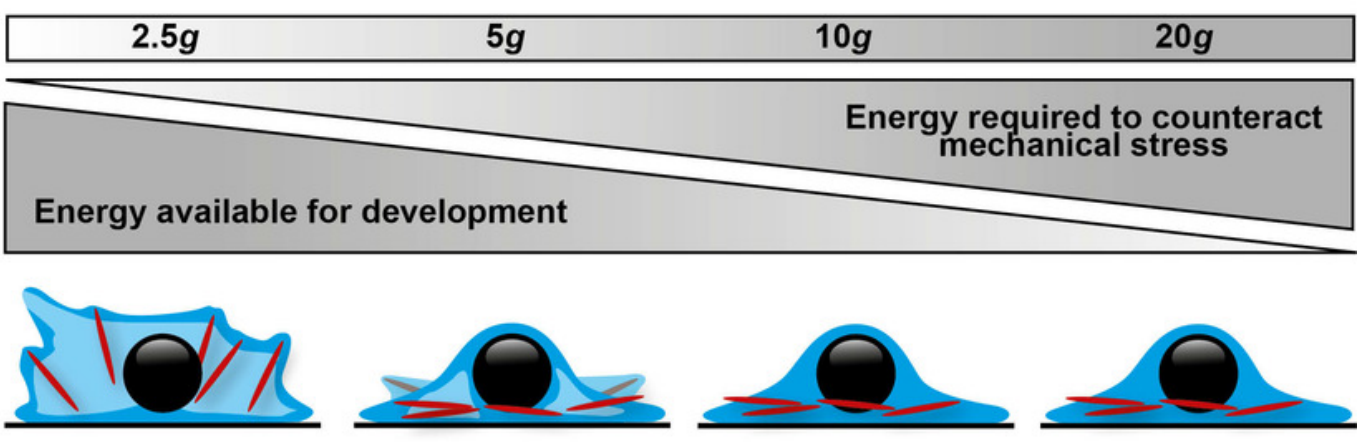

Final configuration with added nutrients
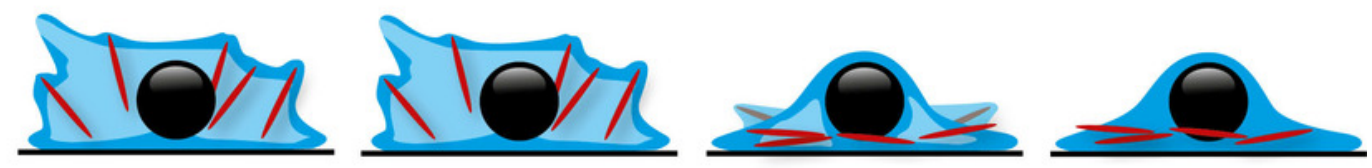

$1 g=9.81 \mathrm{~m} \mathrm{~s}^{-2}$ 
Figure 2

Schematic set-up of the experimental procedure using the large diameter centrifuge (LDC) at the European space agency (ESA), Noordwijk, the Netherlands.

(A) Timeline of the experiment. (B) Configuration of the LDC gondolas (top-view). The LDC has four arms each of which can accommodate two gondolas carrying the well plates with the gemmules. When the centrifuge is spun, the gondolas swing out at an angle $(\theta)$ and a hypergravity field $\left(g_{\text {eff }}\right)$ inside the gondolas is created by the centripetal forces due to the rotation. 


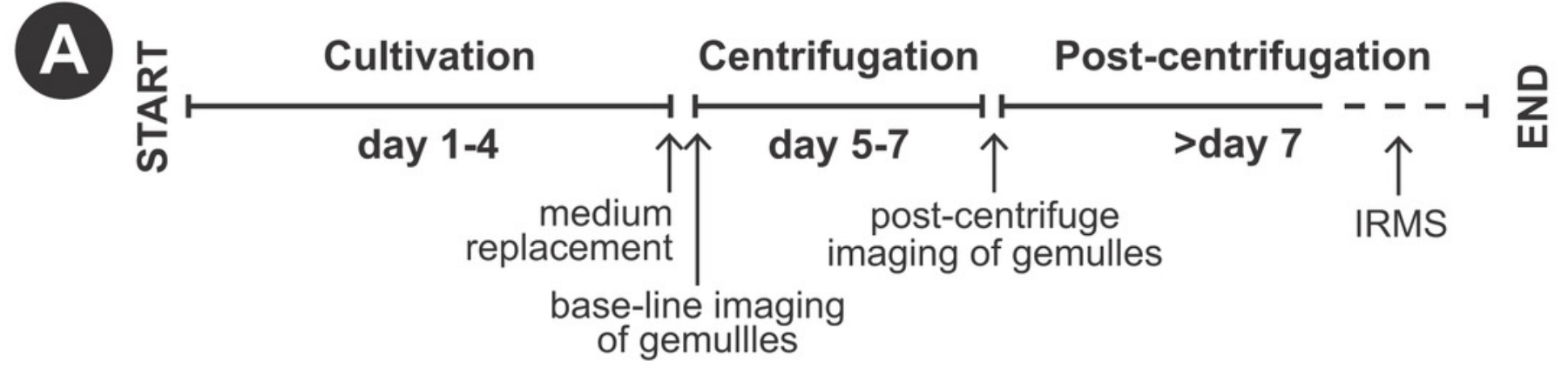

\section{B}

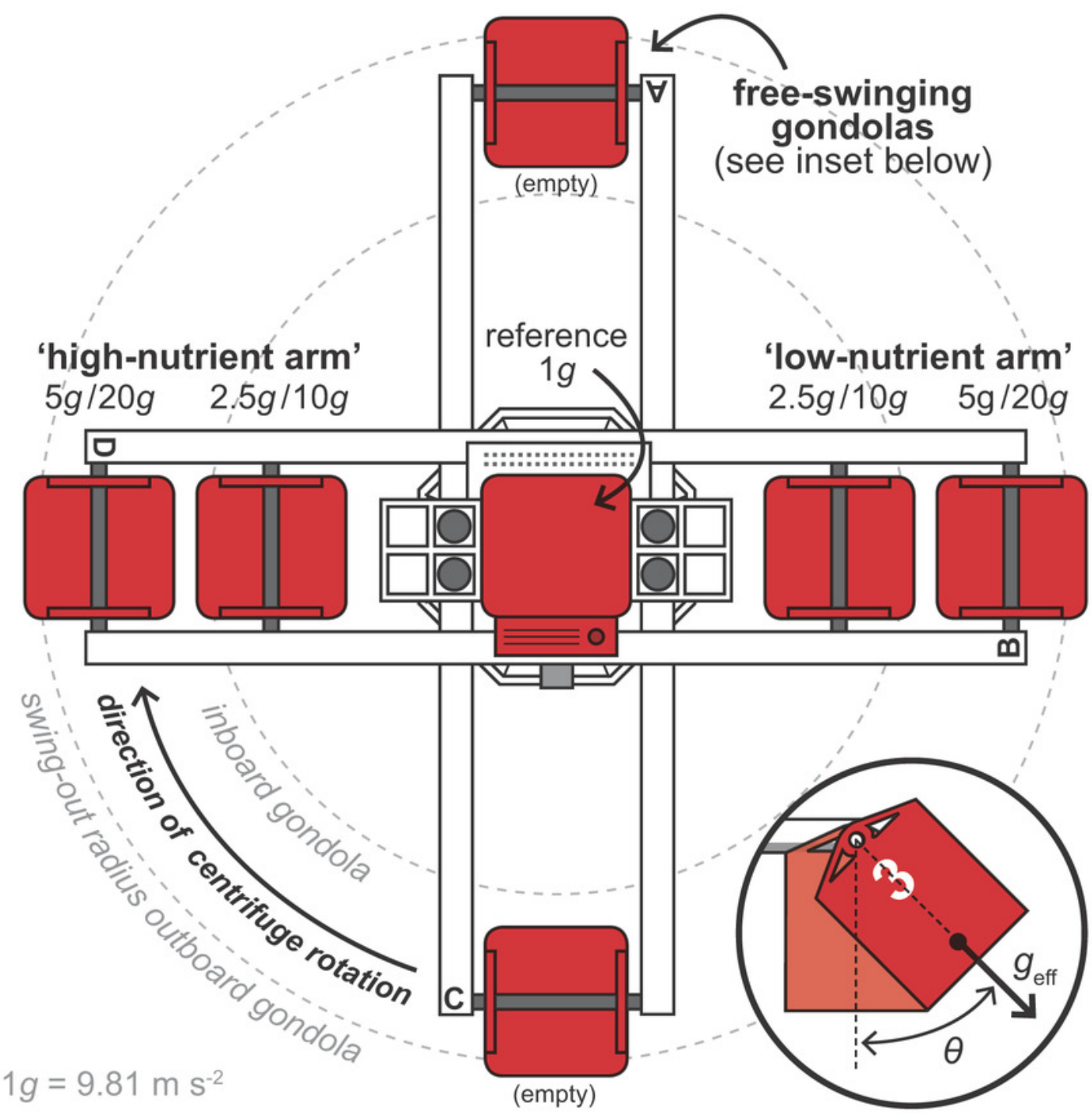




\section{Figure 3}

Spicule skeleton in developing $E$. fluviatilis gemmules under different hypergravity forces.

(A) Sponges photographed after the LDC centrifugation. Note that although surface area decreases with gravity level, under all hypergravity forces the sponges managed to produce spicules, set-up their three-dimensional skeleton and form an osculum. (B) Zoomed-in photographs of osculum formation and spicules after $48 \mathrm{~h}$ exposure to $20 \mathrm{xg}$.
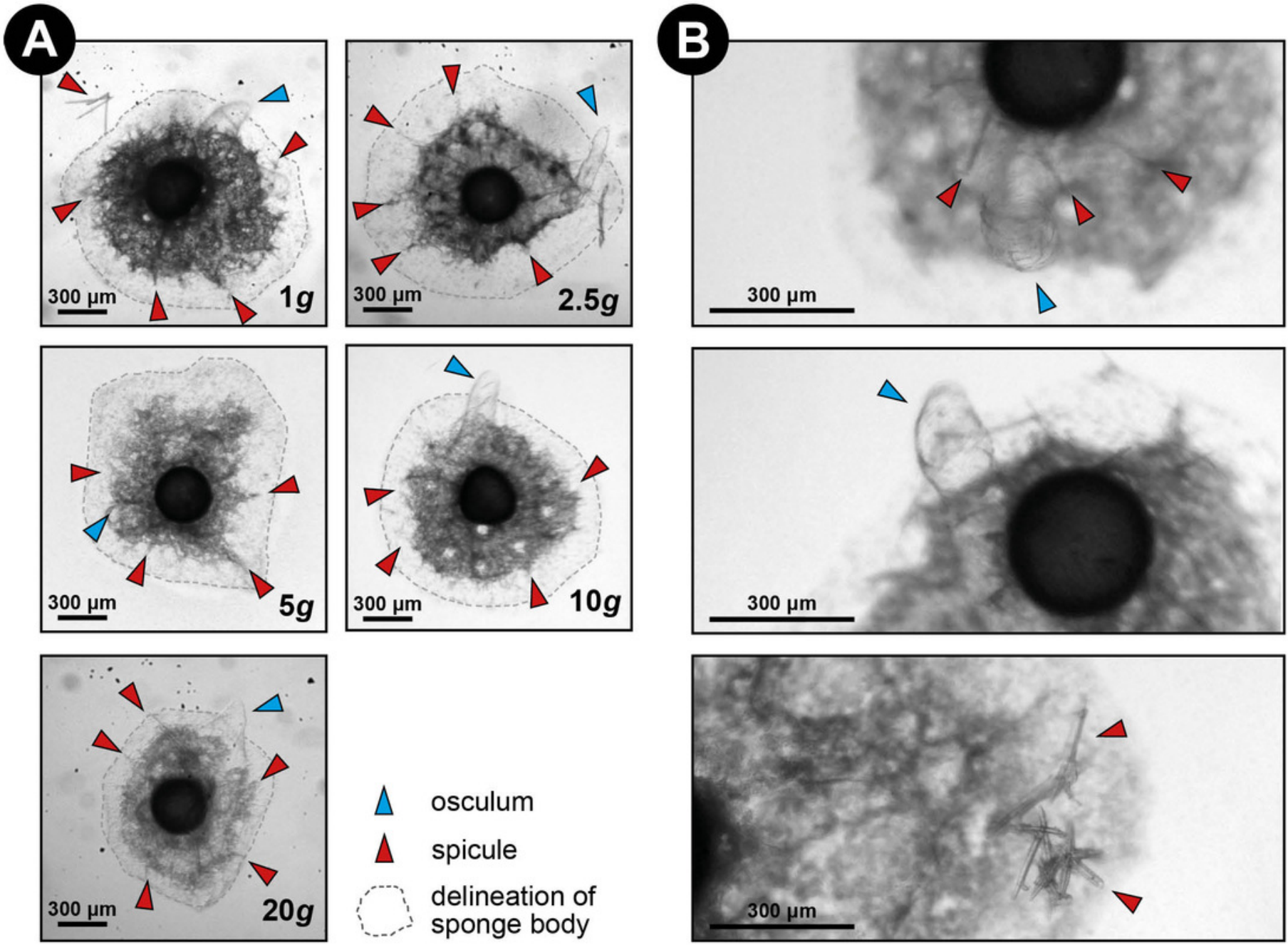

$$
\begin{array}{ll}
\Delta & \text { osculum } \\
\Delta & \text { spicule } \\
\hdashline & \text { delineation of } \\
& \text { sponge body }
\end{array}
$$

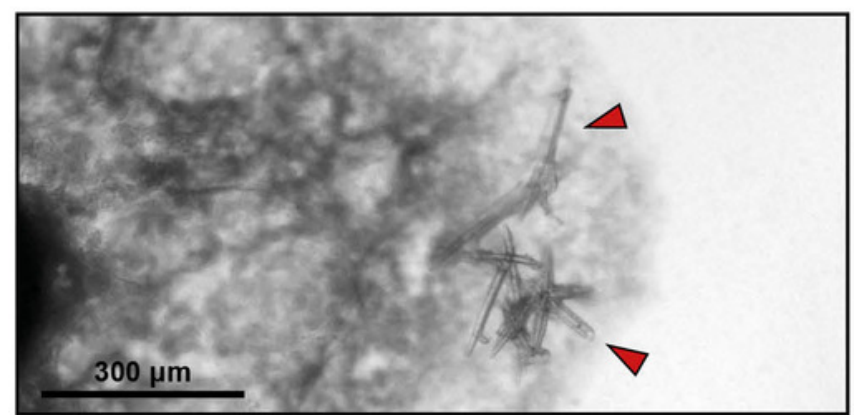


Figure 4 (on next page)

Substrate area cover increase in fed and non-fed E. fluviatilis gemmules under different hypergravity conditions.

The average surface area cover increase (\% of initial size) of fed $(n=22,20,25,29,26$ respectively for $1,2.5,5,10$, and $20 \times g)$ and non-fed $(n=24,21,21,19,20$ respectively for $1,2.5,5,10$, and $20 \times g$ ) sponges under the different hypergravity forces. Error bars represent standard errors of the mean. 
Figure 5 (on next page)

Incorporation of isotopically-enriched $\left({ }^{13} \mathrm{C}\right.$ and $\left.{ }^{15} \mathrm{~N}\right)$ amino acids in developing $E$. fluviatilis.

Average incorporation rates are expressed as $\mu \mathrm{mol} \mathrm{C}$ or $\mathrm{N}_{\text {tracer }} \mathrm{mmol}_{\text {sponge }}{ }^{-1} \mathrm{~d}^{-1} \cdot n=22,20,25$, 29, 26 respectively for respectively for $1,2.5,5,10$, and $20 \times \mathrm{g}$. The dotted line represents average uptake across all $g$ force levels. Error bars represent standard errors of the mean. Asterisk indicates significant difference compared to uptake at $1 \times \mathrm{g}$. 
